\title{
Research
}

\section{Under-provision of medical care for vascular diseases for people with dementia in primary care:}

\author{
a cross-sectional review
}

\section{Abstract \\ Background \\ Vascular diseases contribute to the causation and progression of clinical dementia.}

Aim

To evaluate the quality of medical care for vascular diseases provided to people with dementia, the patient and practice characteristics that influence quality, and to compare care with that provided to those without dementia.

\section{Design and setting}

Observational, cross-sectional review of primary care records of people with dementia from 52 general practices from five primary care trusts in the UK, and comparison with publicly available summary data on patients without dementia.

\section{Method}

A total of 700 patients with $\geq 1$ diagnosed vascular disease or risk factor were identified from dementia registers. Quality of care was measured on 30 indicators from the UK Quality and Outcomes Framework (QOF) for hypertension, coronary heart disease, stroke, diabetes mellitus, atrial fibrillation, heart failure, and smoking. Overall quality of vascular care was calculated for each patient with dementia.

\section{Results}

Level of care received by people with dementia was significantly lower compared with those without dementia for 22 of 30 (73\%) indicators; most notably for measurement processes such as peripheral pulses check and neuropathy testing for diabetes, and cholesterol measures for stroke. Among people with dementia, women those in care homes, and those with fewer comorbid physical conditions and medications were associated with lower scores for overall quality of vascular care.

\section{Conclusion}

The quality of medical care provided to people with dementia with regard to vascular diseases is not concordant with quality, as defined by the QOF. Research is needed to improve access to high-quality care.

\section{Keywords}

dementia; general practice; health care; quality indicators; vascular diseases.

\section{INTRODUCTION}

An estimated 821884 people have dementia in the UK.' Compared with older people without dementia, people with Alzheimer's disease and other dementia subtypes have significantly reduced survival; ${ }^{2-4}$ this may, in part, be explained by the presence of comorbid vascular diseases, including congestive heart failure, ischaemic heart disease, diabetes, and cerebrovascular disease. ${ }^{5,6}$ Incidence of recurrent stroke is doubled in people with dementia. ${ }^{7}$ Whether other comorbid conditions are more frequent and underdiagnosed in people with dementia is debated ${ }^{8-10}$ and not all studies have found comorbid vascular diseases to predict a more rapid progression of dementia, ${ }^{11}$ however, there is some evidence that controlling high blood pressure, atrial fibrillation, and angina may slow cognitive decline in dementia. ${ }^{12}$

Patient characteristics that have been associated with better quality of care include older age, greater dementia severity, ${ }^{13}$ and greater comorbidity, although the latter's relationship with quality of care is not entirely clear. ${ }^{14-16}$ Compared with people living in the community, those living in care homes receive poorer care for conditions like heart disease and diabetes, and potentially harmful medications (for example, antipsychotics) are overprescribed. ${ }^{17-19}$ Practice characteristics such as small list

A Connolly, BSc (Hons), research assistant; E Gaehl, BSc (Hons) MRes, research assistant; R Drake, BSc, PhD, MRCPsych, senior lecturer, Mental Health and Neurodegeneration Research Group, University of Manchester, Manchester. S Campbell, BA, MA, PhD, professor of primary care research, University of Manchester, Manchester. J Morris, BSc, MSc, head of medical statistics, University Hospital of South Manchester, Manchester. H Martin, MRCGP, DRCOG, GP, Ashville Surgery, Manchester. S Iliffe, FRCGP, FRCP, professor of primary care for older people, University College London, London. N Purandare, PhD, DPM, DGM, MD, MRCPsych, FRCPsych, professor and honorary consultant in size, low level of socioeconomic deprivation, ${ }^{20}$ and a large number of GPs ${ }^{21}$ have also been associated with better quality of care for people with dementia.

The gaps in the quality of care for people with dementia are documented in terms of:

- the detection rates of dementia, and associated behavioural and psychological symptoms of dementia; $22-24$

- end-of-life care; ${ }^{25}$ and

- care provided to those in care homes. ${ }^{26}$

A few studies based in secondary and long-term care settings have also found suboptimal care for individual comorbid diseases such as acute myocardial infarction, ${ }^{27}$ prevention of secondary or recurrent stroke, ${ }^{28,29}$ and atrial fibrillation. ${ }^{29}$

Primary care services are the first point of contact and main healthcare service for people with dementia. ${ }^{30-32}$ It has been shown that the quality of annual reviews done in primary care for dementia is suboptimal and, despite a high prevalence of vascular diseases, over one-quarter of individuals diagnosed with dementia are prescribed antipsychotic medications that are known to increase the risk of cerebrovascular accidents and mortality. ${ }^{33}$ In the current study, the quality of care for vascular conditions and risk factors received by

old age psychiatry, University of Exeter, Exeter. Address for correspondence

Amanda Connolly, Level 4, Building 17, Monash University, Wellington Road, Clayton, Victoria, Australia.

E-mail: ajconnolly3dagmail.com

Submitted: 7 May 2012; Editor's response: 8 June 2012; final acceptance: 31 August 2012. @British Journal of General Practice

This is the full-length article (published online 28 Jan 2013) of an abridged version published in print. Cite this article as: Br J Gen Pract 2013; DOI: 10.3399/bjgp13X663046 


\section{How this fits in}

Vascular diseases are important in predicting the progression of dementia, including Alzheimer's disease, and contribute to increased risk for mortality. Suboptimal quality of care in the treatment of individual vascular diseases, such as myocardial infarction or stroke, in people with dementia has previously been studied; however, none of the studies has investigated or combined the quality of care received by people with dementia who have comorbid vascular disease or risk factors across multiple domains. Despite high levels of vascular-related comorbidity and equitable intermediate outcomes, this study found that a greater proportion of people with dementia, compared with those without dementia, do not receive provision for routine care measurements outlined in Quality and Outcomes Framework targets for vascular diseases and risk factors. These findings support further research on the unique clinical and organisational challenges to the commissioning and administration of routine medical care for vascular-related conditions for people who have dementia, especially those who are living in care homes.

people with dementia within primary care were evaluated, together with the patientand practice-level factors associated with it.

\section{METHOD}

The study sample selection and dataextraction methods have previously been described in detail. ${ }^{33}$ In brief, primary care electronic and paper records of 1006 people with dementia from dementia registers of a stratified random sample of 52 general practices from five primary care trusts (PCTs) in Greater Manchester were examined by trained researchers, using a proforma tool designed and piloted for the study purpose. From these, 12 people who had revoked diagnoses or were deceased were excluded. People with dementia I $n=700$ ) who were diagnosed to have at least one of the vascular diseases or risk factors were included in the current analyses (Figure 1). Data collected included patient demographics lage, sex, living situation), subtype of dementia, comorbid physical and mental health conditions, current medications, and all recorded consultations and tests.

\section{Quality-of-care measures}

To measure quality of care received for vascular diseases and risk factors, 30 quality indicators for hypertension, coronary heart disease, stroke/transient ischaemic attack (TIA), diabetes mellitus, atrial fibrillation, heart failure, and smoking were used. These were taken from the UK Quality and Outcomes Framework (QOF) guidelines for general-practice remuneration. ${ }^{34}$

A total quality-of-vascular-care score was calculated for each patient as follows:

$$
\begin{aligned}
& \text { number of relevant indicators for } \\
& \text { which care was provided } \\
& \hline \text { number of indicators for which } \\
& \text { the patient was eligible }
\end{aligned}
$$

Not all indicators applied to all patients. Expressed as a percentage, the score represents the proportion of indicators adhered to for each patient, within a range of $0-100 \%$. This approach has been used in studies of overall quality of care for major chronic diseases; ${ }^{35}$ it gives each patient equal weight, regardless of the number of indicators for which they are eligible. ${ }^{35,36} \mathrm{All}$ quality indicators were treated equally as all those that were appropriate should have been recorded.

\section{Comparison data on patients without dementia}

The study obtained information on the number of patients who were eligible for (that is, all patients on each disease register, including those with dementia), and who had met, each QOF indicator in each participating practice from online QOF 2008/2009 databases (NHS: Health and Social Care Information Centre [NHSIC], www.ic.nhs.uk).

Practices have the capacity to remove individual patients from the calculations of practice achievement for specific indicators; for example, if a patient is unsuitable for treatment or is newly registered with the practice. This is called 'exception reporting'. Achievement levels were adjusted to incorporate the number of patients with dementia who were exception reported in relevant indicator denominators lobtained from NHSIC online databases), as this information was not originally collected as part of the study.

For each indicator, the numbers of people with dementia with a record of an indicator being met and those eligible for it were subtracted from the numerator and denominator respectively, creating a 'without-dementia' comparison group. For example, if 35000 out of 40000 individuals with hypertension received a bloodpressure check, and 300 out of 400 people 


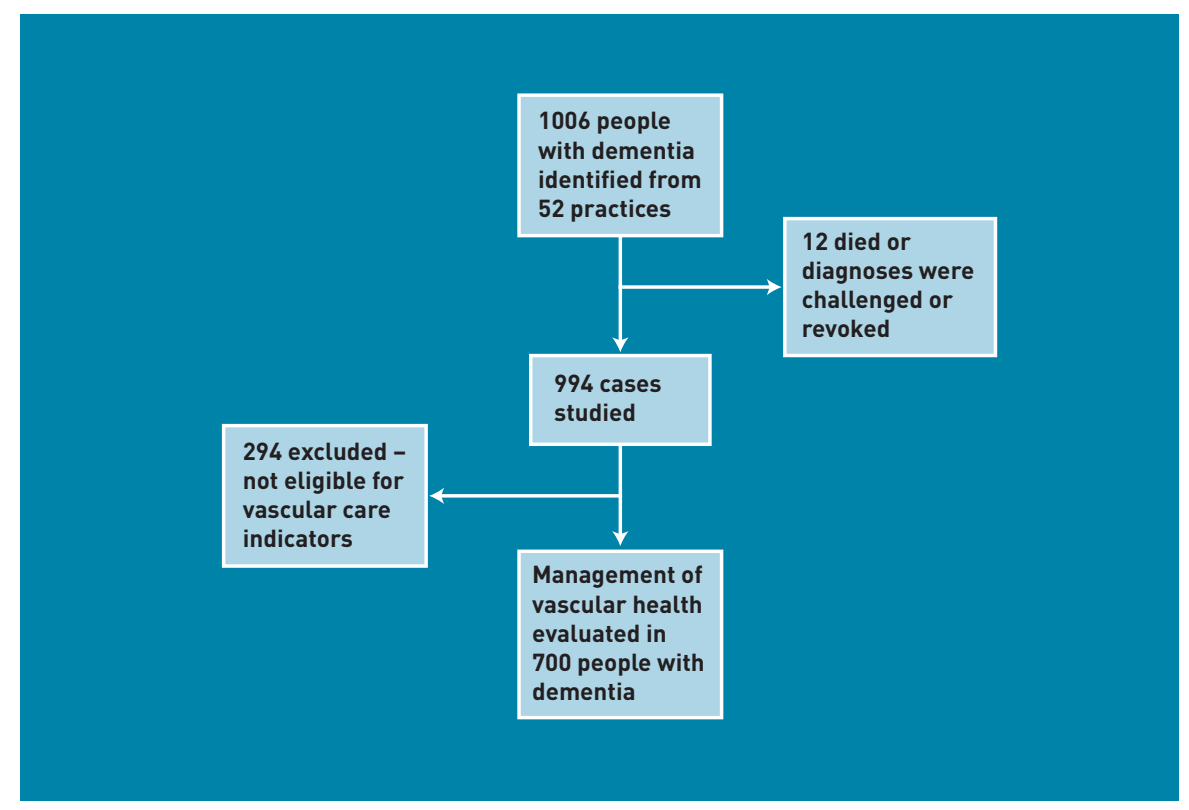

Figure 1. Selection of people with dementia eligible for vascular care. with dementia and hypertension also did; then this would leave 34700 (35000 - 300) out of 39600 (40000 - 400) individuals without dementia.

\section{Statistical analysis}

Descriptive statistics were analysed using SPSS for windows (version 16.0). The proportion of people with dementia who had received care for each quality indicator from those who were eligible for it was calculated. Comparisons between the care received by people with dementia and that of all other patients with the disease (not known to have dementia) for all 30 QOF vascular indicators were made using Pearson $\chi^{2}$ tests lor Fisher's exact test, where a cell size was $<5$ ), with a Bonferroni correction of the alpha level (0.05) for the multiple comparisons.

To investigate the factors influencing total quality of vascular care, multilevel linear regression analysis was used, as it deals with a lack of independence within clusters, such as patients grouped into practices and practices grouped into PCT. ${ }^{37,38}$ There were three levels in the multilevel analyses: patient, practice, and PCT.

Univariate associations were initially explored, with patient-level and practicelevel independent variables. Patient-level variables were

- age;

- sex;

- dementia duration;

- living situation (living in nursing/care home versus community);
- comorbid physical conditions;

- medications; and

- dementia subtype (Alzheimer's disease, including mixed dementia, vascular dementia, and other dementia).

Practice-level variables were:

- whether the practice was run by one GP (single-handed) versus several (multihanded);

- socioeconomic deprivation of practice location, as measured by the Index of Multiple Deprivation 2007;39 and

- the size of the registered population aged $>65$ years

Multivariate models adjusting for all variables were then analysed. A normalising transformation could not be applied to the non-normally distributed dependent variable used in these analyses. Although regression analysis has been found to be reasonably robust to some nonnormality, ${ }^{40}$ sensitivity of the main analyses were assessed by using a multilevel logistic model with a median-split outcome variable. No differences in significance were identified, hence, the main analysis is reported. All multilevel modelling analyses were performed using Stata (version 11.0).

\section{RESULTS}

\section{Demographics}

The study sample included 700 people with dementia (female $66 \%$, mean [standard deviation, SD] age 82.1 [8.0] years) from 52 general practices (mean [SD] list size 7418 [3405]). Each patient had $\geq 1$ comorbid conditions covered by at least one of the 30 indicators for vascular care (Table 1). The median duration of dementia since diagnosis was 2.8 years (interquartile range [IQR] 1.4-4.9 years), 52\% lived in their own homes, and 531 (76\%) showed evidence of multimorbidity ( $\geq 2$ comorbidities, vascular or non-vascular, in addition to dementia). Among vascular-related conditions, hypertension (63\%) was most frequent, followed by coronary heart disease (28\%), stroke/TIA (24\%), and diabetes (20\%).

\section{Quality of care for vascular diseases and risk factors}

Table 2 shows quality of recorded care for each of the 30 indicators for vascular care in those with and without dementia. For 26 of $30(87 \%)$ indicators, a lower proportion of people with dementia received the required quality of care, 


\section{Table 1. Characteristics of people with dementia $(n=700)$}

\begin{tabular}{|c|c|}
\hline Characteristic & Value \\
\hline Age, years, mean (SD), range $43-102$ & $82.1(8.0)$ \\
\hline Male, \% & 239 (34) \\
\hline Dementia duration in years, median (IQR), range $0-31$ & $2.8(1.4-4.9)$ \\
\hline \multicolumn{2}{|l|}{ Dementia subtype $(\%)$} \\
\hline Alzheimer's disease & $255(36)$ \\
\hline Vascular & 233 (33) \\
\hline Mixed & $61(9)$ \\
\hline Lewy bodies & $21(3)$ \\
\hline Other & $18(3)$ \\
\hline Unspecified & $112(16)$ \\
\hline \multicolumn{2}{|l|}{ Living situation (\%) } \\
\hline Nursing/care home & 262 (37) \\
\hline Nursing home & $114(16)$ \\
\hline Community & $361(52)$ \\
\hline At home with carer & $153(22)$ \\
\hline Home alone & $60(9)$ \\
\hline Unknown & $148(21)$ \\
\hline Unknown & $77(11)$ \\
\hline Number of medications prescribed, mean (SD), range 0-25 & 7.6 (3.9) \\
\hline \multicolumn{2}{|l|}{ Comorbid conditions } \\
\hline Number of physical conditions, median (IQR) & $2.0(2.0-3.0)$ \\
\hline Patients with multimorbidity, $\geq 2$ conditions (\%) & $531(76)$ \\
\hline \multicolumn{2}{|l|}{ Cardiovascular related $(\%)$} \\
\hline Hypertension & $440(63)$ \\
\hline Coronary heart disease & $195(28)$ \\
\hline Stroke or TIA & $169(24)$ \\
\hline Diabetes & $137(20)$ \\
\hline Atrial fibrillation & $99(14)$ \\
\hline Heart failure & $46(7)$ \\
\hline \multicolumn{2}{|l|}{ Other physical (\%) } \\
\hline Arthritis & $237(34)$ \\
\hline Cancer, current or past & $76(11)$ \\
\hline Respiratory disease & $129(18)$ \\
\hline Kidney disease & 125 (18) \\
\hline \multicolumn{2}{|l|}{ Practice characteristics, $n=52$ (SD) } \\
\hline Number of GPs, mean & $5.2(3.2)$ \\
\hline Practice deprivation, mean & 28.5 (18.2) \\
\hline List size, mean & 7418 (3405) \\
\hline Population aged $>65$ years, mean & $1224(1014)$ \\
\hline
\end{tabular}

$I Q R=$ interquartile range. $S D=$ standard deviation. $T I A=$ transient ischaemic attack total cholesterol $\leq 5 \mathrm{mmo} / / \mathrm{l}$ for diabetes; and blood pressure $\leq 150 / 90 \mathrm{mmHg}$ for coronary heart disease. This was also the case for treatment indicators relating to the prescribing of angiotensin-converting enzyme (ACE) inhibitors or angiotensin receptor blockers for heart failure, and receiving flu vaccine in the preceding winter for diabetes, stroke, and coronary heart disease respectively.

\section{Predictors of quality of vascular care}

The median quality-of-vascular-care score for people with dementia was 67\% (IQR 45-89). In univariate analyses (Table 3), better total vascular care was significantly associated with male sex, greater number of comorbid physical conditions, living in the community compared with living in a care home, vascular dementia subtype, and greater number of medications. There were no significant practice-level predictors.

In the multivariate model, being male, having greater physical comorbidity, living in the community (compared with in a nursing/care home), and having a greater number of medications remained significantly associated with better quality of vascular care.

\section{DISCUSSION}

\section{Summary}

The study findings showa greater proportion of people with dementia, compared with those without dementia, do not receive routine care measurements outlined in QOF targets for vascular diseases and risk factors. This was particularly so for process, rather than intermediate or treatment outcomes, and despite high levels of vascular comorbidity. Among people with dementia, women, individuals living in care homes, and those with less comorbid physical conditions and medications appear to be the most disadvantaged.

\section{Strengths and limitations}

The practices were selected through a random stratified sampling process. All patients on dementia registers were included; however, dementia may remain undiagnosed in up to $50 \%$ of patients, which could have led to underestimation of true effect. ${ }^{41}$ Measures of care that rely on the evaluation of medical records, such as history taking, have been associated with poorer overall quality of care ${ }^{42}$ and medical records may not give an accurate reflection of the actual care provided. However, documented care is, in itself, a measure of quality. 43

GPs perceive people with dementia as 


\begin{tabular}{|c|c|c|c|c|c|}
\hline Quality of ca & are indicator & $\begin{array}{c}\text { With } \\
\text { dementia, } \\
n(\%)\end{array}$ & $\begin{array}{c}\text { Without } \\
\text { dementia, } \\
n(\%)\end{array}$ & $\begin{array}{l}\text { Difference, } \\
\%\end{array}$ & $\chi^{2}$ \\
\hline \multicolumn{6}{|c|}{ Hypertension } \\
\hline HT 4 & $\mathrm{BP}^{\mathrm{a}}$ & 324 (74) & 37742 (91) & -17 & $P<0.001$ \\
\hline HT 5 & $\mathrm{BP}$ is $\leq 150 / 90 \mathrm{mmHg}$ & 294 (67) & 32238 (77) & -10 & $P<0.001$ \\
\hline \multicolumn{6}{|c|}{ Coronary heart disease } \\
\hline CHD 5 & $\mathrm{BP}^{\mathrm{a}}$ & $167(86)$ & 11978 (97) & -11 & $P<0.001$ \\
\hline $\mathrm{CHD} 6$ & $\mathrm{BP}$ is $\leq 150 / 90 \mathrm{mmHg}^{b}$ & $161(83)$ & 11004 (89) & -6 & $P=0.005$ \\
\hline CHD 7 & Total cholesterol ${ }^{b}$ & $113(68)$ & 11339 (92) & -24 & $P<0.001$ \\
\hline $\mathrm{CHD} 8$ & Total cholesterol $\leq 5 \mathrm{mmol} / \mathrm{L}^{\mathrm{b}}$ & $110(56)$ & 9459 (77) & -21 & $P<0.001$ \\
\hline CHD 11 & $\begin{array}{l}\text { Patients with a history of myocardial } \\
\text { infarction (diagnosed after } 1 \text { April 2003) } \\
\text { currently treated with an ACE inhibitor } \\
\text { or angiotensin II antagonist }{ }^{c}\end{array}$ & $11(52)$ & $1523(84)$ & -32 & $P<0.001$ \\
\hline CHD 12 & $\begin{array}{l}\text { Record of influenza immunisation in the } \\
\text { preceding } 1 \text { September-31 March }\end{array}$ & $152(78)$ & $9890(80)$ & -2 & $P=0.493$ \\
\hline \multicolumn{6}{|l|}{ Stroke/TIA } \\
\hline STROKE 5 & $\mathrm{BP}^{\mathrm{b}}$ & 139 (82) & $5084(96)$ & -14 & $P<0.001$ \\
\hline STROKE 6 & $\mathrm{BP}$ is $\leq 150 / 90 \mathrm{mmHg}$ & $130(77)$ & 4621 (87) & -10 & $P<0.001$ \\
\hline STROKE 7 & Total cholesterol ${ }^{b}$ & $92(54)$ & 4708 (89) & -35 & $P<0.001$ \\
\hline STROKE 8 & Last total cholesterol $\leq 5 \mathrm{mmol} / \mathrm{l}^{\mathrm{b}}$ & $73(43)$ & $3746(70)$ & -27 & $P<0.001$ \\
\hline STROKE 10 & $\begin{array}{l}\text { Record of influenza immunisation in the } \\
\text { preceding } 1 \text { September-31 March }\end{array}$ & $131(78)$ & 3977 (75) & 3 & $P=0.494$ \\
\hline \multicolumn{6}{|l|}{ Diabetes } \\
\hline DM 2 & $\mathrm{BMI}^{\mathrm{b}}$ & $81(61)$ & 11835 (92) & -31 & $P<0.001$ \\
\hline DM 5 & $\mathrm{HbA1} c^{b}$ & $101(74)$ & $12085(94)$ & -20 & $P<0.001$ \\
\hline DM 7 & Last $\mathrm{HbA} 1 \mathrm{c}$ is $\leq 10^{\mathrm{b}}$ & 98 (72) & $11371(88)$ & -16 & $P<0.001$ \\
\hline DM 9 & Presence or absence of peripheral pulses & b 53 (39) & 10665 (83) & -46 & $P<0.001$ \\
\hline DM 10 & Neuropathy testing ${ }^{b}$ & $51(37)$ & 10523 (82) & -45 & $P<0.001$ \\
\hline DM 11 & $\mathrm{BP}^{\mathrm{b}, \mathrm{c}}$ & $115(84)$ & 12445 (97) & -13 & $P<0.001$ \\
\hline DM 12 & Last $\mathrm{BP}$ is $\leq 145 / 85 \mathrm{mmHg}$ & $116(85)$ & 10085 (79) & 4 & $P=0.083$ \\
\hline DM 16 & Total cholesterol ${ }^{b}$ & 113 (83) & 12062 (94) & -11 & $P<0.001$ \\
\hline DM 17 & Last total cholesterol $\leq 5 \mathrm{mmol} / \mathrm{L}^{\mathrm{b}}$ & $96(70)$ & 9967 (78) & -8 & $P=0.038$ \\
\hline DM 18 & $\begin{array}{l}\text { Record of influenza immunisation in the } \\
\text { preceding } 1 \text { September-31 March }\end{array}$ & 113 (83) & $9855(77)$ & 6 & $P=0.116$ \\
\hline DM 20 & Last $\mathrm{HbA} 1 \mathrm{c}$ is $\leq 7.5^{\mathrm{b}}$ & 74 (54) & $8323(65)$ & -11 & $P=0.010$ \\
\hline DM 21 & Retinal screening ${ }^{b}$ & 53 (39) & 10891 (85) & -46 & $P<0.001$ \\
\hline DM 22 & eGFR or serum creatinine testing ${ }^{b}$ & $112(82)$ & 12141 (95) & -13 & $P<0.001$ \\
\hline \multicolumn{6}{|c|}{ Atrial fibrillation } \\
\hline AF 3 & $\begin{array}{l}\text { Patients with AF currently treated with } \\
\text { anticoagulation/anti-platelet therapy }\end{array}$ & $75(76)$ & $3693(91)$ & -15 & $P<0.001$ \\
\hline \multicolumn{6}{|c|}{ Heart failure } \\
\hline HF 3 & $\begin{array}{l}\text { Patients with a current diagnosis of HF } \\
\text { due to LVD currently treated with ACE } \\
\text { inhibitor or angiotensin receptor blocker }\end{array}$ & $2(100)$ & $1200(83)$ & 17 & $P=0.527$ \\
\hline \multicolumn{6}{|l|}{ Smoking } \\
\hline SMOKE 3 & $\begin{array}{l}\text { CHD, stroke/TIA, HT, DM, COPD or } \\
\text { asthma patients, whose notes record } \\
\text { smoking status }^{b}\end{array}$ & $172(82)$ & 64256 (95) & -13 & $P<0.001$ \\
\hline SMOKE 4 & $\begin{array}{l}\text { CHD, stroke/TIA, HT, DM, COPD or } \\
\text { asthma patients, who smoke whose } \\
\text { notes have record of smoking cessation } \\
\text { advice/referral to specialist offered }{ }^{b, c}\end{array}$ & $23(48)$ & 11247 (92) & -44 & $P<0.001$ \\
\hline \multicolumn{6}{|c|}{ 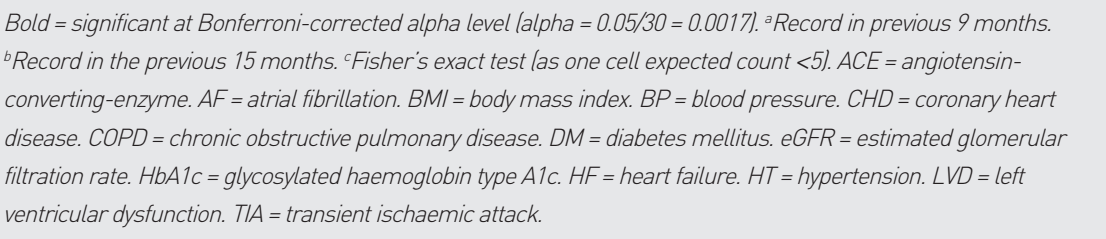 } \\
\hline
\end{tabular}




\section{Table 3. Multilevel linear regression results of the univariate and multivariate predictors of total quality of vascular care}

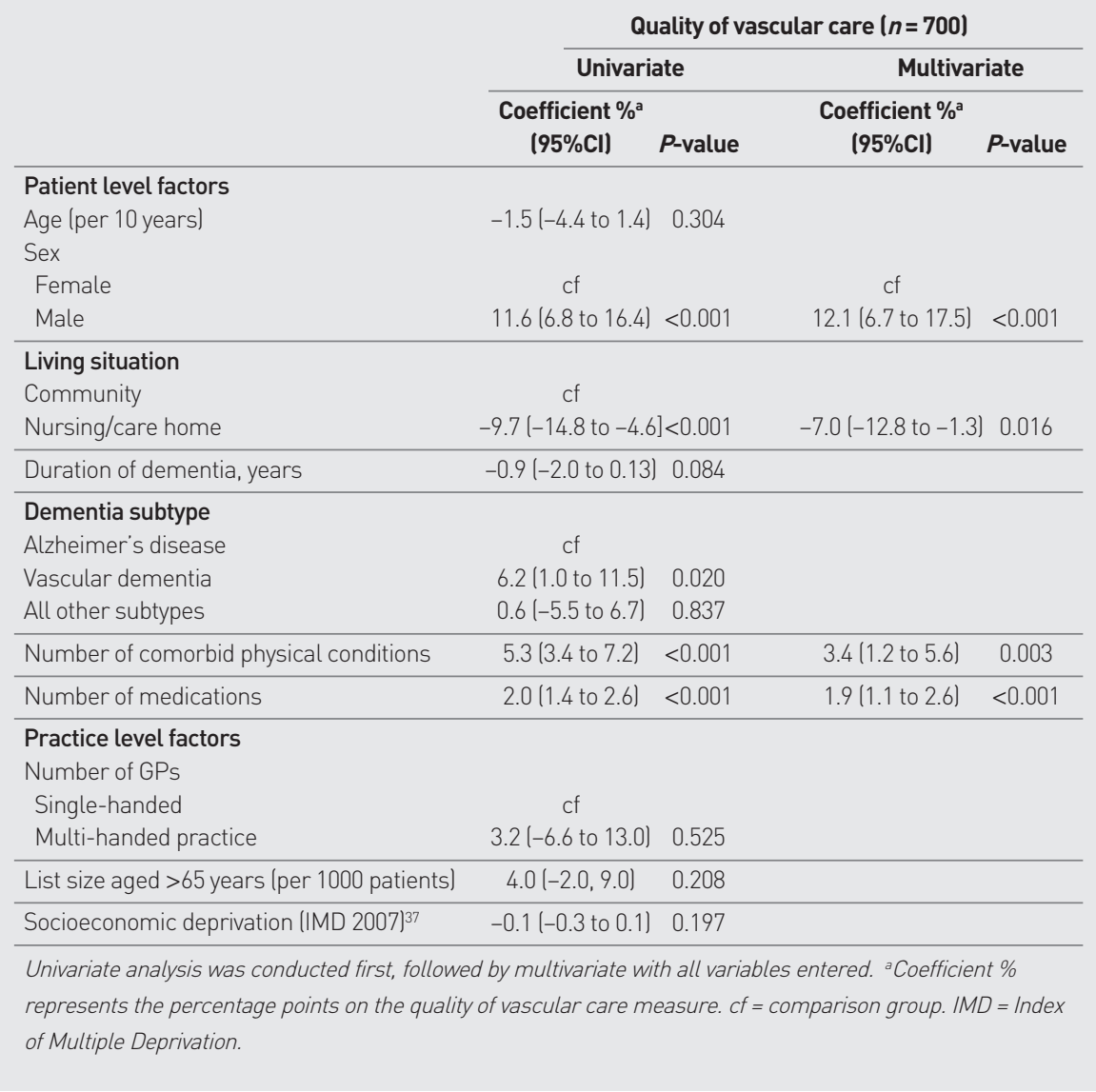

being more difficult to manage and less amenable to improvements in quality of life, compared with patients who have heart disease and diabetes; ${ }^{44}$ this may result in the undertreatment and less aggressive management of medical conditions. ${ }^{45}$ How far this reflects GPs' judgements that aggressive treatment is inappropriate, given the prognosis of a patient with dementia, or caution about exposing patients to sideeffects of preventative drugs, is unclear. This could lead to higher numbers of those with dementia being exception reported. No statistics regarding people with dementia who were exception reported from vascular-related disease indicators were found. However, it is worth noting that the 2008/2009 exception reporting rate for the QOF indicator for dementia lan annual review for patients on dementia registers onlyl was $7.64 \%$; this is higher than the average for all clinical domains (4.87\%). ${ }^{46}$

Demographic confounders, such as age and sex, could not be controlled for in the comparisons between patients with and without dementia. There is evidence that older age groups are less likely to receive guideline-recommended therapies for treatment of conditions such as acute myocardial infarction. ${ }^{47}$ However, age discrimination in healthcare services should not take place, and will be banned by future laws as part of the Equality Act. ${ }^{48}$ Previous research comparing people from older age groups, with and without dementia, has shown dementia to be independently associated with poor quality of care..$^{24-27}$ The findings of association between the quality of care and greater number of comorbid medical conditions and medications may be due to increased likelihood of attendance to consultations. ${ }^{15,24}$

\section{Comparison with existing literature}

The deficiencies in the quality of care received by people with dementia are consistent with previous studies demonstrating suboptimal care received by these patients in secondary and private care settings. ${ }^{24-27}$

Although improved performance in care for individual conditions like diabetes has been apparent in recent years - and since the introduction of the QOF in UK general practice $^{49,50}$ - this is not necessarily true for all subgroups of patients. For example, women and ethnic minority groups are less likely to have targets for diabetes met compared with their counterparts. ${ }^{51}$ The findings suggest that people with dementia are also disadvantaged.

The results showed that patient, but not practice, characteristics were associated with poorer quality of care among those with dementia. The poorer quality of vascular care for those living in care homes is consistent with research on the monitoring of chronic diseases and appropriate drug treatment. ${ }^{17}$

Previous research has identified a reduced ability to recall and communicate symptoms or adverse effects, ${ }^{45}$ decreased decisionmaking capacity, and treatment adherence ${ }^{52}$ as potential challenges in addressing health needs in those with dementia. QOF targets may be more difficult to complete in those with dementia, which may explain poor performance on indicators that require greater compliance from patients (for example, retinal screening); however, this is not the case for all indicators (for example, physical examination for peripheral pulses), suggesting that poor quality cannot be explained by patient-level factors alone.

The management of vascular disease and diabetes for people with dementia was equitable or better on targets for intermediate outcomes and treatment in some areas, suggesting effective clinical intervention, for 
example heart-failure therapy and diabetes control. However, observations of better control of blood pressure, cholesterol, and $\mathrm{HbA1c}$ levels are in keeping with natural physiological changes that occur in people with dementia, such as declining blood pressure, and cholesterol levels. ${ }^{53-55}$ Poorer process but better intermediateoutcomes indicators suggest that the latter should not be used on their own to assess quality of care in people with dementia. The more favourable performance of patients with dementia who have had an influenza vaccination compared to those patients without dementia may be due to Department of Health recommendations offering the vaccination to all persons aged $\geq 65$ years. ${ }^{56}$

\section{Implications for practice}

It remains a concern that a significant proportion of people with dementia fail to receive appropriate vascular care, such as cholesterol checks in stroke, especially considering the increased likelihood of recurrent stroke ${ }^{7}$ and that control of vascular diseases may slow cognitive decline. ${ }^{10,57}$ Improving equity of access to good quality medical care is underpinned by, for example, the Care Quality Commission, ${ }^{58}$
Healthcare Improvement Scotland, ${ }^{59}$ and the National Dementia Strategies for England ${ }^{60}$ and Scotland. ${ }^{61}$ Educational interventions developed for general practices may be one potential strategy, as they have already been shown to improve detection of dementia, ${ }^{62}$ and trials are underway to improve overall clinical management and adherence to management guidelines. ${ }^{63}$ The findings suggest that further research should focus on the unique clinical and organisational challenges to the commissioning and administration of routine medical care for comorbid vascular diseases in people with dementia, especially those who are living in care homes.

This study has quantified the quality of care received by people with dementia for vascular-related diseases and risk factors. The findings add to the growing literature, which highlights disparities in care for people with dementia, suggesting deficiencies in a number of areas in care for vascular-related health and sub-groups of people with dementia, who may be receiving the poorest care. Such information is important if the many challenges faced by primary healthcare services in the care for people with dementia are taken into consideration.

the decision to submit the manuscript for publication.

\section{Ethical approval}

The project was approved by the Caldicott Guardians of each participating primary care trust. Ethical approval was not required as the data were collected to measure clinical practice.

\section{Provenance}

Freely submitted; externally peer reviewed.

\section{Competing interests}

The authors have declared no competing interests.

\section{Acknowledgements}

Professor Nitin Purandare passed away during the preparation of this manuscript. He will be sadly missed by his friends and colleagues. We thank Vonda Hamilton and Michelle Griffiths (Manchester PCT); Robert Hallworth (Stockport PCT); Reehana Khan (Oldham PCT); Angela Christopher, Michelle Garret, and Sharon Mott (Ashton, Wigan and Leigh PCT); Paul Campbell and Lesley Gray (Bury PCT); and Christine Atkinson (Bolton PCT) for their help in data collection.

\section{Discuss this article}

Contribute and read comments about this article on the Discussion Forum: http://www.rcgp.org.uk/bjgp-discuss 


\section{REFERENCES}

1. Luengo-Fernandez R, Leal J, Gray A. Dementia 2010: the economic burden of dementia and associated research funding in the United Kingdom. Cambridge: Alzheimer's Research Trust, 2010.

2. Rait G, Walters K, Bottomley $C$, et al. Survival of people with clinical diagnosis of dementia in primary care: cohort study. BMJ 2010; 341: c3584.

3. Molsa PK, Marttila RJ, Rinne UK. Long-term survival and predictors of mortality in Alzheimer's disease and multi-infarct dementia. Acta Neurol Scand 1995; 91(3): 159-164.

4. Fitzpatrick AL, Kuller LH, Lopez OL, et al. Survival following dementia onset: Alzheimer's disease and vascular dementia. J Neurol Sci 2005; 229-230: 43-49.

5. Gambassi G, Landi F, Lapane KL, et al. Predictors of mortality in patients with Alzheimer's disease living in nursing homes. J Neurol Neurosurg Psychiatry 1999; 67(1): 59-65.

6. Larson EB, Shadlen MF, Wang $L$, et al. Surivival after initial diagnosis of Alzheimer's Disease. Ann Intern Med 2004; 140(7): 501-509.

7. Moroney JT, Bagiella MS, Tatemichi TK, et al. Dementia after stroke increases the risk of long-term stroke recurrence. Neurology 1997; 48(5): 1317-1325.

8. Schubert CC, Boustani M, Callahan CM, et al. Comorbidity profile of dementia patients in primary care: are they sicker? J Am Geriatr Soc 2006; 54(1): 104-109.

9. Zekry D, Herrmann FOR, Grandjean R, et al. Demented versus nondemented very old inpatients: the same comorbidities but poorer functional and nutritional status. Age Ageing 2008; 37(1): 83-89.

10. Fu C, Chute DJ, Farag ES, et al. Comorbidity in Dementia. Arch Pathol Lab Med 2004; 128(1): 32-38.

11. Regan C, Katona C. Walker Z, et al. Relationship of vascular risk to the progression of Alzheimer disease. Neurology 2006; 67(8): 1357-1362.

12. Mielke MM, Rosenberg PB, Tschanz J, et al. Vascular factors predict rate of progression in Alzheimer disease. Neurology 2007; 69(19): 1850-1858.

13. Chodosh J, Mittman BS, Connor Kl, et al. Caring for patients with dementia: how good is the quality of care? Results from three health systems. J Am Geriatr Soc 2007; 55(8): 1260-1268.

14. Higashi T, Wenger NS, Adams JL, et al. Relationship between number of medical conditions and quality of care. N Engl J Med 2007; 356(24): 24962504.

15. Min LC, Wenger N, Fung C, et al. Multimorbidity is associated with better quality of care among vulnerable elders. Med Care 2007; 45(6): 480-488.

16. Redelmeier DA, Tan SH, Booth GL. The treatment of unrelated disorders in patients with chronic medical diseases. N Engl J Med 1998; 338(21): 15161520.

17. Fahey T, Montgomery AA, Barnes J, Protheroe J. Quality of care for elderly residents in nursing homes and elderly people living at home: controlled observational study. BMJ 2003; 326(7389): 580.

18. Sibley A, MacKnight $C$, Rockwood K, et al. The effect of the living situation on the severity of dementia at diagnosis. Dement Geriatr Cogn Disord 2002 13(1): $40-45$

19. Benbow SJ, Walsh A, Gill GV. Diabetes in institutionalised elderly people: a forgotten population? BMJ 1997; 314(7098): 1868-1869.

20. Campbell SM, Hann M, Hacker J, et al. Identifying predictors of high quality care in English general practice: observational study. BMJ 2001; 323(7316): 784-787.

21. Hippisley-Cox J, Pringle M, Coupland C, et al. Do single handed practices offer poorer care? Cross sectional survey of processes and outcomes. BMJ 2001; 323(7308): 320-323.

22. Connolly A, Gaehl E, Martin H, et al. Underdiagnosis of dementia in primary care: variations in the observed prevalence and comparisons to the expected prevalence. Aging Ment Health 2011; 15(8): 978-984.

23. Sampson EL, Blanchard MR, Jones $L$, et al. Dementia in the acute hospital: prospective cohort study of prevalence and mortality. Br J Psychiatry 2009; 195(1): 61-66

24. Chodosh J, Mittman BS, Connor Kl, et al. Caring for patients with dementia: how good is the quality of care? Results from three health systems. J Am Geriatr Soc 2007; 55(8): 1260-1268.

25. Sampson EL, Gould V, Lee D, Blanchard MR. Differences in care received by patients with and without dementia who died during acute hospital admission: a retrospective case note study. Age Ageing 2006; 35(2): 187-189.
26. Ballard C, Fossey J, Chithramohan R, et al. Quality of care in private sector and NHS facilities for people with dementia: cross sectional survey. BMJ 2001; 323(7310): 426-427.

27. Sloan FA, Trogdon JG, Curtis LH, Schulman KA. The effect of dementia on outcomes and process of care for Medicare beneficiaries admitted with acute myocardial infarction. J Am Geriatr Soc 2004; 52(2): 173-1781.

28. Moroney JT, Tseng CL, Paik MC, et al. Treatment for the secondary prevention of stroke in older patients: the influence of dementia status. J Am Geriatr Soc 1999; 47(7): 824-829.

29. Gurwitz JH, Monette J, Rochon PA, et al. Atrial fibrillation and stroke prevention with warfarin in the long-term care setting. Arch Intern Med 1997; 157(9): 978-984.

30. Villars $\mathrm{H}$, Oustric $\mathrm{S}$, Andrieu S, et al. The primary care physician and Alzheimer's disease: an international position paper. J Nutr Health Aging 2010; 4(2): 110-120

31. Callahan CM, Hendrie HC, Tierney WM. Documentation and evaluation of cognitive impairment in elderly primary care patients. Ann Intern Med 1995; 122(6): 422-429.

32. Downs MG. The role of general practice and the primary care team in dementia diagnosis and management. Int J Geriatr Psychiatry 1996; 11(11): 937-942.

33. Connolly A, Iliffe S, Gaehl E, et al Quality of care provided to people with dementia: utilisation and quality of the annual dementia review in general practice. Br J Gen Pract 2012; DOI: 10.3399/bjgp12X625148.

34. NHS Employers and the General Practitioners Committee. Quality and Outcomes Framework guidance for GMS contract 2008/09. London: NHS Confederation (Employers) Company, 2008.

35. Campbell SM, Roland MO, Middleton E, Reeves D. Improvements in quality of clinical care in English general practice 1998-2003: longitudinal observational study. BMJ 2005; 331(7525): 1121.

36. Reeves D, Campbell SM, Adams J, et al. Combining multiple indicators of clinical quality: an evaluation of different analytic approaches. Med Care 2007; 45(6): 489-496.

37. Goldstein H. Multilevel statistical models, 4th edition. West Sussex: John Wiley \& Sons, 2010

38. Greenland S. Principles of multilevel modelling. Int J Epidemiol 2000; 29(1): 158-167.

39. Communities and Local Government. Index of multiple deprivation. 2007 [updated 2007; cited 28th June 2010]. http://www.imd.communities.gov.uk/ laccessed 11 Dec 2012).

40. Ali MM, Sharma SC. Robustness to nonnormality of regression F-tests. J Econometrics 1996; 71(1-2): 175-205.

41. Connolly A, Gaehl E, Martin H, et al. Underdiagnosis of dementia in primary care: variations in the observed prevalence and comparisons to the expected prevalence. Aging Ment Health 2011; 15(8): 978-984.

42. Min LC, Reuben DB, MacLean CH, et al. Predictors of overall quality of care provided to vulnerable older people. J Am Geriatr Soc 2005; 53(10): 17051711.

43. Chodosh J, Solomon DH, Roth CP, et al. The quality of medical care provided to vulnerable older patients with chronic pain. J Am Geriatr Soc 2004; 52(5): 756-761

44. Harris DP, Chodosh J, Vassar SD, et al. Primary Care Provider's views of challenges and rewards of dementia care relative to other conditions. J Am Geriatr Soc 2009; 57(12): 2209-2216.

45. Farrell MJ, Katz B, Helme RD. The impact of dementia on the pain experience. Pain 1996; 67(1): 7-15.

46. The NHS Information Centre Prescribing Support Unit. Quality and Outcomes Framework Exception Data 2008/09. The NHS Information Centre, 2009. http://www.ic.nhs.uk/statistics-and-data-collections/auditsand-performance/the-quality-and-outcomes-framework/the-quality-andoutcomes-framework-exception-reporting-2008-09 (accessed 11 Dec 2012).

47. Rathore SS, Mehta RH, Wang Y, et al. Effects of age on the quality of care provided to older patients with acute myocardial infarction. Am J Med 2003; 114(4): 307-315.

48. Equality Act 2010: banning age discrimination in services, public functions and associations. A consultation on proposed exceptions to the ban. London: Government Equalities Office, 2011.

49. Doran T, Fullwood C, Gravelle H, et al. Pay-for-performance programs in family practices in the United Kingdom. N Engl J Med 2006; 355(4): 375-384. 
50. Doran T, Fullwood C, Kontopantelis E, Reeves D. Effect of financial incentives on inequalities in the delivery of primary clinical care in England: analysis of clinical activity indicators for the quality and outcomes framework. Lancet 2008; 372(9640): 728-36

51. Alshamsan R, Millett C, Majeed A, Khunti K. Has pay for performance improved the management of diabetes in the United Kingdom? Prim Care Diabetes 2010; 4(2): 73-78.

52. Brauner DJ, Muir JC, Sachs GA. Treating nondementia illnesses in patients with dementia. JAMA 2000; 283(24): 3230-3235.

53. Stewart $R$, White $L R, X u e ~ Q-L$, Launer LJ. Twenty-six-year change in total cholesterol levels and incident dementia: the Honolulu-Asia Aging Study. Arch Neurol 2007; 64(1): 103-107.

54. Skoog I, Nilsson L, Persson G, et al. 15-year longitudinal study of blood pressure and dementia. Lancet 1996; 347(9009): 1141-1145.

55. Solomon A, Kareholt I, Ngandu T, et al. Serum cholesterol changes after midlife and late-life cognition: twenty-one-year follow-up study. Neurology 2007; 68(10): 751-756.

56. Department of Health. Immunisation against infectious disease. In: The Green Book. London: Department of Health, 2012. http://immunisation. dh.gov.uk/gb-ch-19-influenza/ laccessed 12 Dec 2012).
57. Deschaintre Y, Richard F, Leys D, Pasquier F. Treatment of vascular risk factors is associated with slower cognitive decline in Alzheimer disease. Neurology 2009; 73(9): 674-680.

58. Care Quality Commission. About the Care Quality Commission. London: CQC, 2009.

59. Healthcare Improvement Scotland. Annual Report 2011. Edinburgh: NHS Scotland, 2011

60. Department of Health. Living well with dementia: a National Dementia Strategy. London: DoH, 2009

61. The Scottish Government. Scotland's National Dementia Strategy. Edinburgh: The Scottish Government, 2010.

62. Downs M, Turner S, Bryans M, et al. Effectiveness of educational interventions in improving detection and management of dementia in primary care: cluster randomised controlled study. BMJ 2006; 332(7543): 692-696.

63. Iliffe S, Wilcock J, Griffin M, et al. Evidence-based interventions in dementia: a pragmatic cluster-randomised trial of an educational intervention to promote earlier recognition and response to dementia in primary care (EVIDEM-ED). Trials 2010; 11: 13. 